\title{
Assessment of Infection Control Measures at Primary Health Care Facilities in Egypt
}

\author{
Hoda Ibrahim Ibrahim Rizk, Hanan Abd-Elghani EL-Raghi, Marwa M. Zein (D)* \\ Department of Public Health and Community Medicine, Faculty of Medicine, Cairo University, Cairo, Egypt
}

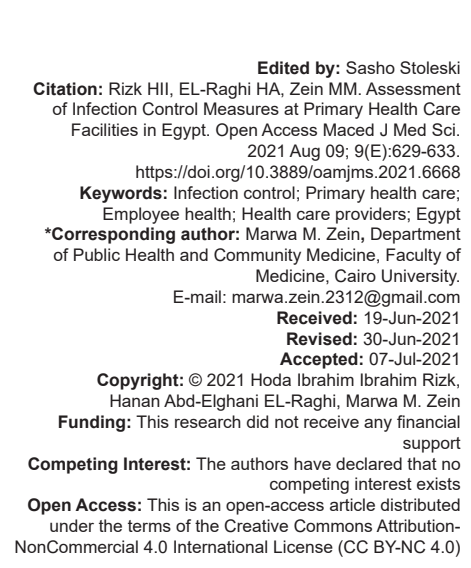

\section{Introduction}

Healthcare-associated infection (HCAI) is a major global safety concern for both patients and health care providers (HCPs). $\mathrm{HCAl}$ is an infection occurring to a patient during the process of care in a hospital or other health care facility which was not present or incubating at the time of admission. HCAI can affect patients at any type of setting where they receive care and can also appear after discharge. HCAl includes also occupational infections among health facility staff [1].

Although the care provided in most primary health care $(\mathrm{PHC})$ facilities is predominantly ambulatory with few or no inpatient beds, infection control (IC) is still important to minimize or eliminate the risks of facility-acquired infections and assure quality patient care [2].

The core set of health services delivered by the reformed health system in Egypt is called "the Basic Benefit Package" which is the masterpiece of the Family Health Model. Health facility accreditation is mandatory before contracting with a family health fund through four steps. The final accreditation is based on measuring eight categories, IC program is one of them [3].

The strategic plan for the IC program included setting up an organizational structure, IC guidelines, training health care workers, promoting occupational safety, and establishing a system for monitoring and evaluation [4]

Primary care facilities (PHCs) are public sector facilities and public sector facilities are the only option available to most low-income groups, who constitute most of Egypt's population. Improving the IC situation in $\mathrm{PHCs}$ leads to improving the quality of services provided and the entire health status of the population. Despite the availability of the national IC assessment tool, it is not covering certain items such as the part related to the HCPs so it is crucial to assess its comprehensiveness with the international tool to help in the provision of a simple and comprehensive method.

\section{Aim of the study Goal Improve IC situation in PHC facilities.}




\section{Specific objectives}

The study was conducted in three Egyptian PHC facilities with the following objectives:

1. Compare items of assessment of IC measures between national and international assessment tool of IC in PHC

2. Assessment of IC measures in $\mathrm{PHC}$ by national assessment tool

3. Explore hand hygiene $(\mathrm{HH})$ compliance among HCPs

4. Explore the fulfillment of $\mathrm{HH}$ supplies.

\section{Methods}

\section{Study design}

Health system operations research, exploratory

study.

\section{Study setting}

The study was conducted at three Egyptian PHC facilities at Cairo and Giza governorate.

\section{Sample type and subjects of the study}

Convenient sample (easy access) including three PHC facilities in urban (Masr El-Quadema), semi-urban (El-Zahraa), and rural (Shabramant) areas. All HCPs in each facility were interviewed with a total number (55 doctors and 34 nurses).

\section{Data collection tools and technique}

The IC was assessed by the following tools.

1. The national assessment tool for $\mathrm{PHC}$ facilities [5] was first developed by the team of IC of the Egyptian ministry of health in 2006. The latest version which was developed in 2015 was the one used in this study. It includes five major items for assessment (administrative activity, cleaning activities, infrastructure, supplies, and procedures) with a total of 484 points which were divided into (34 points for administrative activity, 46 points for cleaning activities, 36 points for infrastructure, 40 points for supplies, and 328 points for procedures) then the total points were converted into a percentage to facilitate its interpretation

2. Structured interview questionnaire derived from the international IC assessment tool for PHC facilities [2], used to collect data from doctors, nurses, and workers.
Observation checklists derived from the international tool of assessment

a. Hand hygiene station checklist: It assessed the availability of hand hygiene stations; the availability of the hand hygiene supplies and their quality

b. Hand hygiene practice checklist: It assessed the adherence of the HCPs to hand hygiene practice in each facility. This checklist was used by observing the HCP either doctor or nurse who contacted a patient, the type of patient contact either invasive or not, the type of hand hygiene before and after patient contact either handwashing with soap and water or alcohol hand rub or none.

If the HCP do hand hygiene either hand wash or alcohol hand rub another checklist was used to assess if this hand hygiene was correct or not based on criteria of correct hand hygiene; hands-free of jewelry and other accessories, sleeves above the elbow, avoiding contamination of hands when switching off the taps and taking at least 30 seconds doing hand wash.

\section{Data analysis technique}

All the collected data were revised for completeness and logical consistency. Pre-coded data was entered on the computer using Microsoft Office Excel Software Program 2017. Pre-coded data was then transferred and entered into the Statistical Package of Social Science Software program, version 26 (SPSS) to be analyzed statistically.

For qualitative variables, they were described as frequency and percentage and compared using the Chi-square test, where the $p<0.05$

Ethical considerations: All the interviewed staff was treated according to the Helsinki Declaration of biomedical ethics. Verbal consent was obtained from each interviewed staff after proper orientation regarding the objectives of the study. The protocol was approved by the faculty of medicine at Cairo university's ethical committee, public health department council staff, and the ministry of health.

\section{Results}

1. Comparison between items of national and international IC assessment tools in $\mathrm{PHC}$ facilities Table 1 represents a content analysis of national and international IC assessment tools in PHC facilities. Most items of assessment were found in both tools except for the assessment of HCP safety (presence of employee health program, employee 
health education program, monitoring of sharp injuries, the presence of strategies to prevent sharp injuries, and pre-employment TB screening). Some items were not present in both tools such as facility demographics (number of staff, types of procedures, average number of clients).

Table 1: Comparison between items of national and international IC assessment tools in PHC facilities

\begin{tabular}{|c|c|c|}
\hline Items & National assessment tool & International assessment tool \\
\hline $\begin{array}{l}\text { Facility demographics (number } \\
\text { of staff, types of procedures, } \\
\text { average number of clients) }\end{array}$ & Not present & Not present \\
\hline \multicolumn{3}{|l|}{ IC program } \\
\hline IC program and infrastructure & Present & Present \\
\hline Training and competence & Present & Present \\
\hline HCP safety & Not present & Present \\
\hline $\begin{array}{l}\text { Standard precautions } \\
\text { assessment }\end{array}$ & Present & Present \\
\hline $\begin{array}{l}\text { Total items and sub items of } \\
\text { assessment }\end{array}$ & $\begin{array}{l}5 \text { items and } 102 \text { sub } \\
\text { items }\end{array}$ & 9 modules and 156 questions \\
\hline Number of pages & 5 pages & 45 pages \\
\hline
\end{tabular}

2. IC assessment according to the national assessment tool

Figure 1 remarks that although the availability of supplies, presence of administrative activities, and good infrastructure, items related to manpower practice (procedures and cleaning activities) had the lowest percent score.

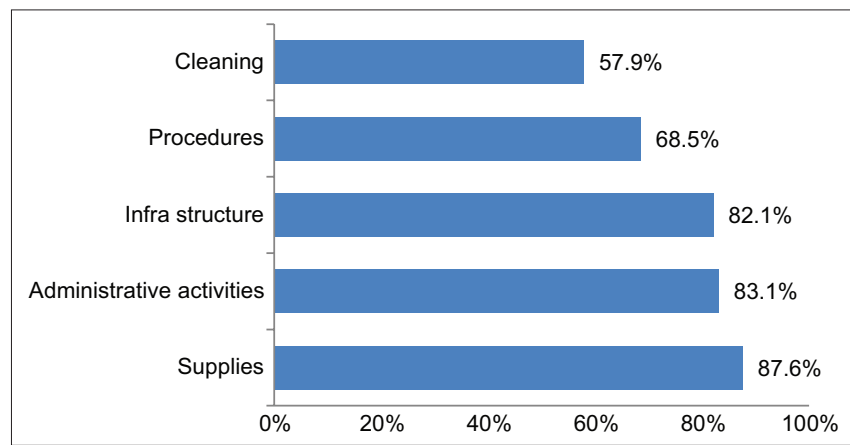

Figure 1: Average total percent score of the studied PHC facilities in items of the national IC assessment tool

3. IC assessment according to the international assessment tool stations:

Regarding the observation of hand hygiene

Table 2 illustrates the total percent score of the hand hygiene stations regarding the fulfillment of the required criteria (availability of supplies and sink condition). The total percent score was $73.3 \%$. The least score was for the presence of hand hygiene posters $(47.1 \%)$ followed by sink cleanness and the presence of alcohol-based hand antiseptics (both $58.8 \%$ ).

Regarding the assessment of IC committee activities towards the protection of HCPs against acquired infections in the facility:

Table 3 showed that the nurses' positive response $(73.5 \%)$ towards the presence of formal employee health program was significantly more than the doctors' positive response $(46.2 \%)(p=0.02)$, $85.2 \%$ of the nurses said that there is employee health education program in their facilities. While half of the doctors said that there is an employee health education program and the other half denies that $(p=0.002)$.

Table 2: Percent score of observation checklist for assessment of hand washing supplies and sinks condition

\begin{tabular}{|c|c|}
\hline Items of assessment & Total score $(\%)$ \\
\hline Presence of hand washing station & $15 / 17^{*}(88.2)$ \\
\hline \multicolumn{2}{|l|}{ Supplies } \\
\hline Running water available & $15 / 17(88.2)$ \\
\hline Liquid soap present & $15 / 17(88.2)$ \\
\hline Type of dispensers** & $11 / 17(64.7)$ \\
\hline Liquid dispensers in a clean condition & $13 / 17(76.5)$ \\
\hline Method of drying*** & $11 / 17(64.7)$ \\
\hline Presence of alcohol-based hand antiseptic & $10 / 17(58.8)$ \\
\hline Presence of poster on hand wash & $8 / 17(47.1)$ \\
\hline \multicolumn{2}{|l|}{ Sink condition } \\
\hline Sink is clean & $10 / 17(58.8)$ \\
\hline Taps are not leaking & $15 / 17(88.2)$ \\
\hline Drainage pipes are not leaking & $14 / 17(82.4)$ \\
\hline Total score $(\%)$ & $137 / 187(73.3)$ \\
\hline
\end{tabular}

The hepatitis $B$ vaccination status among doctors and nurses; $80 \%$ of the doctors and $91.1 \%$ of the nurses were fully vaccinated against HBV (three doses) $(p<0.001)$, as shown in Table 3.

Table 3: Assessment of IC committee activities towards protection of HCPs against acquired infections in the facility

\begin{tabular}{|c|c|c|c|c|c|}
\hline \multirow[t]{2}{*}{ Item } & \multicolumn{2}{|l|}{ Doctors } & \multicolumn{2}{|l|}{ Nurses } & \multirow[t]{2}{*}{ p-value } \\
\hline & $\mathrm{n}(/ 55)$ & $\%$ & $\mathrm{n}(/ 34)$ & $\%$ & \\
\hline \multicolumn{6}{|l|}{ Presence formal employee health program } \\
\hline Present & 25 & 45.50 & 25 & 73.50 & \multirow[t]{2}{*}{0.02} \\
\hline Not present & 30 & 54.50 & 9 & 26.50 & \\
\hline \multicolumn{6}{|c|}{ Presence employee health education program } \\
\hline Yes & 28 & 50.90 & 29 & 85.30 & \multirow[t]{2}{*}{0.002} \\
\hline No & 27 & 49.10 & 5 & 14.70 & \\
\hline \multicolumn{6}{|l|}{ Hepatitis $B$ vaccine } \\
\hline No vaccine & 4 & 7.3 & 1 & 3.0 & \multirow[t]{4}{*}{$<0.001$} \\
\hline One dose & 1 & 1.8 & 0 & 0.0 & \\
\hline Two doses & 6 & 10.9 & 2 & 5.9 & \\
\hline Three doses & 44 & 80.0 & 31 & 91.1 & \\
\hline \multicolumn{6}{|c|}{ Presence of assigned person to call in an event of sharp injury } \\
\hline Present & 20 & $37 \%$ & 29 & 84.10 & \multirow[t]{2}{*}{$<0.001$} \\
\hline Not present/don't know & 35 & $63 \%$ & 5 & 15.90 & \\
\hline \multicolumn{6}{|c|}{ Monitoring employee punctures and sharp injuries } \\
\hline Yes & 11 & $19.4 \%$ & 15 & 43.4 & \multirow[t]{2}{*}{0.03} \\
\hline No/Do not know & 44 & $80.3 \%$ & 19 & 56.6 & \\
\hline \multicolumn{6}{|l|}{ Pre-employment tuberculin test assessment } \\
\hline Had the baseline tuberculin test & 1 & $1.8 \%$ & 3 & 8.8 & \multirow[t]{2}{*}{0.3} \\
\hline Did not had baseline tuberculin test & 54 & $98.2 \%$ & 31 & 91.2 & \\
\hline
\end{tabular}

Regarding the assessment of Hand hygiene practice (observation of $\mathrm{HH}$ practice), Table 4 shows the hand hygiene practice of doctors and nurses in the studied PHC facilities. For doctors, only one hand hygiene practice $(1.6 \%)$ was done from 62 hand hygiene chances and 2 hand hygiene (10\%) practices were done from 20 chances for nurses.

\section{Discussion}

Little is known about the risks involved with the most common care procedures in PHC. Procedures that are relatively invasive and may result in adverse effects commonly performed in $\mathrm{PHC}$ include insertion of intrauterine devices, injections, and dental procedures. There is a recognized risk associated with the acquisition of viruses such as hepatitis B and HIV [6]. 
Table 4: Observation of hand hygiene practice of doctors and nurses

\begin{tabular}{|c|c|c|c|c|c|c|c|c|c|c|}
\hline \multirow[t]{3}{*}{$\begin{array}{l}\mathrm{HH} \\
\text { Observation }\end{array}$} & \multirow{3}{*}{$\begin{array}{l}\text { Total } \\
\text { patient } \\
\text { contact }\end{array}$} & \multirow{2}{*}{\multicolumn{2}{|c|}{$\begin{array}{l}\text { Type of patient } \\
\text { contact }\end{array}$}} & \multicolumn{3}{|c|}{$\begin{array}{l}\text { Type of } \mathrm{HH} \text { before } \\
\text { patient contact }\end{array}$} & \multicolumn{3}{|c|}{$\begin{array}{l}\text { Type of } \mathrm{HH} \text { after } \\
\text { patient contact }\end{array}$} & \multirow{3}{*}{$\begin{array}{l}\begin{array}{l}\text { Total } \mathrm{HH} \\
\text { practice }\end{array} \\
\mathrm{n}(\%)\end{array}$} \\
\hline & & & & \multicolumn{2}{|l|}{ Yes } & \multirow[t]{2}{*}{ No } & \multicolumn{2}{|l|}{ Yes } & No & \\
\hline & & Invasive & $\begin{array}{l}\text { Non- } \\
\text { invasive }\end{array}$ & $\begin{array}{l}\text { Hand } \\
\text { wash }\end{array}$ & $\begin{array}{l}\text { Alcohol } \\
\text { rub }\end{array}$ & & $\begin{array}{l}\text { Hand } \\
\text { wash }\end{array}$ & $\begin{array}{l}\text { Alcohol } \\
\text { rub }\end{array}$ & & \\
\hline & 31 & 2 & 29 & 0 & 0 & 31 & 1 & 0 & 30 & $1 / 62(1.6)$ \\
\hline urses & 10 & 9 & 1 & 0 & 0 & 10 & 2 & 0 & 8 & $2 / 20(10)$ \\
\hline
\end{tabular}

Advantages and limitations of national

assessment tool

The advantages were that it was short and well structured (five items and 102 sub-items in five pages), takes short time (the average time to complete it is $2 \mathrm{~h}$ ). While the limitations were that the score of some items (cleaning and infrastructure) is subjective, interpretation of the total score was not available with the tool and the researcher got it from personal communication with the supervisors of IC in the ministry of health, items of clinics assessment are the same despite the difference in the procedures done in each clinic, deficient in the assessment of staff IC knowledge, deficient in detailed observation checklist for the assessment of IC measures e.g. hand hygiene and deficient in items related to assessment of employee health e.g. needle -stick injury notification and documentation.

Regarding employee health program, healthful work environment for the staff and eliminate or minimize occupational exposure to blood-borne pathogens through following exposure control plan [7]. In the current study, by comparing Egyptian national and international IC assessment tools in PHC facilities, it was found that the national tool doesn't include items for assessment of employee health (e.g. control of sharp injuries, monitoring of sharp injuries, and TB screening).

Regarding monitoring and reporting sharp injuries, CDC recommended, in outpatient settings, that the facility should track the blood exposure events, evaluates event data, and develops/implements corrective action plans to reduce the incidence of such events [8]. An estimated 600,000 to one million needle-stick injuries are occurring each year in the world. About half of which went unreported. Therefore, it should be stressed that staff should be encouraged and be supported to report injuries [9]. As depicted from the current study, $63 \%$ of the doctors said that they do not know or there are not assigned person to call in an event of sharp injury compared to the nurse's response $(15.9 \%)(p<0.001)$. More than three-quarters of the doctors $(80.3 \%)$ and more than half of nurses $(56.6 \%)$ said that they don't know or there isn't monitoring to employee puncture and sharp injuries $(p=0.03$ ) as shown in Table 3. The IC committee leaders said that the facility offers the vaccine for all HCPs free of charge.

Regarding the protection of HCPs against TB, the $\mathrm{CDC}$ recommended in outpatient settings to ensure that all HCPs had baseline tuberculosis screening (using tuberculin skin test) before placement. Those with the potential for ongoing exposure to TB receive periodic screening (if negative) at least annually [8]. In the current study, pre-employment baseline tuberculin test assessment as shown in Table 3 almost all the doctors and nurses responded that they did not have a pre-employment tuberculin skin test done $(p=0.3)$.

Malangu and Mngomezulu (2015) conducted a survey in South Africa to describe and compare the tuberculosis IC measures implemented by PHC facilities. They found that around $80 \%$ of facilities complying with a screening of staff members for tuberculosis and the screening of staff members for tuberculosis found that 18 facilities reported 35 cases of tuberculosis among staff members. In the current study, most of the HCPs did not have a pre-employment baseline assessment of TB status using a tuberculin skin test [10].

Hand hygiene is one of the most important elements of IC activities as hand hygiene alone can significantly reduce the risk of cross-transmission of infection in healthcare facilities [11].

Insufficient or very low $\mathrm{HH}$ compliance rates have been reported from both developed and developing countries with mean baseline rates ranging from $5 \%$ to $89 \%$ and an overall average of $38.7 \%$. In addition, the duration of hand cleansing episodes ranged on average from as short as $6.6 \mathrm{~s}$ to $30 \mathrm{~s}$ [12]. In the current study, it was found that the national assessment tool is defective in the detailed observation checklist of hand hygiene practice. The application of the observation checklist of the international tool demarcates that the total hand hygiene practice compliance was $1.6 \%$ of the hand hygiene chances for the doctors and $10 \%$ of the hand hygiene chances for the nurses as displayed in Table 4. In addition to that, all hand hygiene practices that were done did not meet the criteria of correct hand hygiene practice.

\section{Conclusion}

1. The national IC assessment tool of PHC facilities in Egypt is well structured but defective in the assessment of employee health activities related to IC e.g. blood-borne pathogens and TB transmission and how to avoid this transmission

2. Tuberculin skin test as screening of TB for the HCPs is neither done pre-employment nor periodically

3. Despite the availability of supplies for hand hygiene practice and good IC knowledge, compliance was very low during the observation time. 


\section{References}

1. Collins AS. Preventing Health Care Associated Infections Definitions of Health Care-Associated Infections. Ch. 41. Preventing Health Care Associated Infections; 1991. p. 1-29. https://doi.org/10.1097/rlu.0000000000001309

2. Infection Control Assessment Tool for Primary Health Care Facilities; 2013. Available from: http://www.siapsprogram.org. [Last accessed on 2021 Jun 19].

3. Report on the Burden of Endemic Health Care-Associated Infection Worldwide Clean Care is Safer Care; 2011. Available from: http://www.who.int. [Last accessed on 2021 Jun 19].

4. Health System Profile-Egypt. Available from: http:// digicollection.org/hss/en/m/abstract/Js17293e/. [Last accessed on 2021 Jun 05].

5. Available from: https://www.hfgproject.org/wp-content/ uploads/2015/02/infection-control-program-implementationin-egypt-a-process-assessment.pdf. [Last accessed on 2021 Jun 19].

6. Padoveze MC, de Figueiredo RM. The role of primary care in the prevention and control of healthcare associated infections. Rev da Esc Enferm 2014;48(6):1131-7. https://doi.org/10.1590/ s0080-623420140000700023 PMid:25626515

7. Bloodborne Infection from Sharps and Mucocutaneous
Exposure: A Continuing Problem American Nurse. Available from: https://www.myamericannurse.com/bloodborne-infectionfrom-sharps-and-mucocutaneous-exposure-a-continuingproblem. [Last accessed on 2021 Jun 19].

8. MMWR: CDC Guidance for Evaluating Health-Care Personne for Hepatitis B Virus Protection and for Administering Postexposure Management National Prevention Information Network Connecting Public Health Professionals with Trusted Information and Each Other. Available from: https://www.npin. cdc.gov/publication/mmwr-cdc-guidance-evaluating-healthcare-personnel-hepatitis-b-virus-protection-and. [Last accessed on 2021 Jun 19]. https://doi.org/10.1111/ajt.12688

9. Tayaben JL. Compliance with sharps injury prevention guideline among nurses in tertiary care hospitals in the Philippines. Int J Infect Control. 2015;11(2):13172. https://doi.org/10.3396/ijic. v11i2.015.15

10. Malangu N, Mngomezulu M. Evaluation of tuberculosis infection control measures implemented at primary health care facilities in Kwazulu-Natal province of South Africa. BMC Infect Dis. 2015;15(1):117. https://doi.org/10.1186/s12879-015-0773-7 PMid:25887523

11. Mathur P. Hand hygiene: Back to the basics of infection control. Indian J Med Res 2011;134(5):611-20. https://doi. org/10.4103/0971-5916.90985

PMid:22199099

12. Philips BJ. Best practices in infection prevention and control: An international perspective. Br J Anaesth. 2012;109(4):653-4. 